\title{
THE CALCIUM METABOLISM IN A CASE OF HEMOPHILIA *
}

CARL H. LAWS, M.D., AND D. MURRAY COWIE, M.D.

ANN ARBOR, MICH.

C. E., 9 years old, entered the hospital because of sudden enlargement of the right knee. He gave a history of repeated attacks of purpura, at times associated with vomiting and fever. The coagulation time of the blood was found to be two and one-half hours. Shortly after entrance he had a marked attack of purpura, with vomiting and fever; and during his stay in the hospital he had many spontaneous and subcutaneous hemorrhages. His brother, aged 19, was also under observation during part of this time for spontaneous hemorrhage into one knee.

A history of bleeding was obtained as follows: Of this family of twelve children, six girls and six boys, three of the boys were bleeders, one dying in infancy from hemorrhage. The maternal grandmother was a bleeder, and was one of ten children, four girls and six boys, three of whom were bleeders, herself and two brothers. The maternal great grandmother and her brother were the only bleeders in a family of seven children, five girls and two boys; her father (patient's great great grandfather) was a bleeder. Of the patient's family, in the order of birth, the third, fourth and eleventh male children were bleeders, the patient being the eleventh.

These data establish the case from the clinical side as one of hemophilia, with the characteristic transmission coming from the female side through two generations.

The coagulation time was determined by taking 3 c.c. of blood directly from a vein into a 10 c.c. test tube. It was placed in the incubator at $37 \mathrm{C}$. and carefully examined from time to time until the first definite appearance of clotting was observed (see table). During the control period the average coagulation time was two and one-half hours; during the third and fourth day of the calcium feeding period the coagulation time was lengthened two hours. The calcium content of the blood was increased over the control period at this time, as will be seen from the table. During the second control period, that is, after discontinuing the calcium, the coagulation time again returned to two and one-half hours.

The calcium determinations in the blood, urine, feces and food extended over a period of fourteen days. The patient was given a cathartic and put on a milk diet, 7 ounces ( 210 c.c.) accurately measured every two hours for eight feeds, or 56 ounces (1,680 c.c.) daily. The child was kept on this diet for two days before the determinations began.

H. Lyman's $s^{1}$ turbidity method was employed for the calcium determinations. In the case of the feces, blood, and milk we substituted and adapted to our use an oxidation method in place of the incineration method usually used. This method was originated by Professor Willard of the department of chem-

* Read before the Twenty-Eighth Annual Meeting of the American Pediatric Society, held at Washington, D. C., May 8-10, 1916.

* From the Department of Pediatrics, University of Michigan Medical School.

1. Lyman, H.: Jour. Biol. Chem., 1915, 21, 551. 
istry for the estimation of the mineral content of coal and other organic material, the details of which are not yet published.

The first five days' determinations constitute the first control period, the following days the calcium feeding period, during which the patient received calcium lactate, as indicated in the table. Thirteen per cent. of calcium lactate is calcium. Twenty-six gm. of calcium lactate was to have been given dissolved in distilled water. This was equivalent to $3 \mathrm{gm}$. of calcium. After the first dose of $7 \mathrm{gm}$. of calcium lactate the patient complained of considerable epigastric pain, and vomited a small amount. The calcium had to be discontinued. On the seventh day $12 \mathrm{gm}$. of calcium lactate was to have been given in divided doses of $4 \mathrm{gm}$. each, but after the first dose the same symptoms-recurred. The patient was then given a one-day period of rest from the lactate, during which the milk diet was continued. No determinations were made on this day.

Calcium Determinations in the Food, Urine, Feces and Blood

\begin{tabular}{|c|c|c|c|c|c|c|c|c|c|c|}
\hline \multirow[b]{2}{*}{ Day } & \multirow[b]{2}{*}{ Period } & \multicolumn{2}{|c|}{ Food (Milk) } & \multicolumn{3}{|c|}{ Urine } & \multicolumn{2}{|c|}{ Feces } & \multirow[b]{2}{*}{$\begin{array}{c}\text { Calcium } \\
\text { in } \\
\text { 1,000 O.c. } \\
\text { Blood, } \\
\text { Gm. }\end{array}$} & \multirow{2}{*}{$\begin{array}{l}\text { Coagu- } \\
\text { lation } \\
\text { Time, } \\
\mathbf{H . ~ M . ~}\end{array}$} \\
\hline & & $\begin{array}{l}\text { Per } \\
\text { Oent. } \\
\text { Oal- } \\
\text { cium }\end{array}$ & $\begin{array}{c}\text { Total } \\
\text { Cal- } \\
\text { cium, } \\
\text { Gm. }\end{array}$ & C.c. & $\begin{array}{l}\text { Per } \\
\text { Cent. } \\
\text { Oal- } \\
\text { cium }\end{array}$ & $\begin{array}{l}\text { Total } \\
\text { Oal. } \\
\text { cium. } \\
\text { Gm. }\end{array}$ & $\begin{array}{c}\text { Weight, } \\
\text { Gm. }\end{array}$ & $\begin{array}{c}\text { Total } \\
\text { Cal- } \\
\text { cium, } \\
\text { Gm. }\end{array}$ & & \\
\hline 1. & Control & 0.343 & 5.0421 & 297 & $\ldots$ & 0.10048 & 32.01 & 0.5479 & ........ & $\ldots$ \\
\hline 2 & ........... & 0.322 & 5.2245 & 1,080 & $\ldots$ & 0.482 & $\ldots \ldots \ldots$ & ........ & 0.6482 & $2: 35$ \\
\hline 3 & ........... & 0.344 & $\tilde{5.3804}$ & 320 & .. & 0.2322 & $\ldots .$. & ........ & 0.6828 & $2: 32$ \\
\hline 4 & $\ldots$ & 0.328 & 5.3742 & 1,044 & $\ldots$ & 0.7471 & 128.6972 & 3.4045 & 0.66 & $2: 48$ \\
\hline 5 & Galcium & 0.345 & 5.3944 & 832 & $8 \dagger$ & 0.5578 & .. & . & 0.6866 & $2: 35$ \\
\hline 6 & $\underset{*}{\text { Calcium }}$ & 0.849 & 5.5522 & 545 & ... & 0.3777 & 63.334 & 1.85644 & 0.6274 & $1: 50$ \\
\hline 7 & * & 0.347 & 5.4256 & 545 & ... & 0.3277 & 110.9778 & 2,4282 & 0.658 & $3: 30$ \\
\hline 8 & ........... & ...... & $\ldots \ldots$. & ...... & $\cdots$ & ........ & n....... & $\ldots \ldots \ldots$ & ....... & $\cdots$ \\
\hline 9 & $0.65 \mathrm{gm}$ & 0.351 & 5.9085 & 744 & .. & 0.5016 & 277.02 & 6.7102 & 0.665 & $3: 00$ \\
\hline 10 & $0.91 \mathrm{gm}$ & 0.343 & 5.4537 & 855 & .. & 0.5921 & .. & ........ & .0 .6844 & $2: 38$ \\
\hline 11 & $1.17 \mathrm{gm}$. & 0.345 & 5.8111 & 635 & $\ldots$ & 0.4519 & 37.338 & 0.6372 & 0.7192 & $4: 55$ \\
\hline 12 & $1.56 \mathrm{gm}$. & 0.344 & 5.7926 & 242 & 1.5 & 0.6337 & 92.141 & 2.3703 & 0.7545 & $4: 85$ \\
\hline 13 & Control & 0.344 & 5.7879 & 772 & ... & 0.5241 & 260.1684 & 2.7117 & 0.6918 & $2: 45$ \\
\hline 14 & ........... & 0.345 & 5.8044 & 797 & 8 & 0.5102 & 99.875 & 1.814 & 0.6612 & $2: 15$ \\
\hline
\end{tabular}

* The patient vomited the calcium lactate. The calcium was calculated as 13 per cent of the lactate. t Percentage of total periods.

On the ninth day the patient was given $1 \mathrm{gm}$. of calcium lactate every two hours for five doses, which is equivalent to $0.65 \mathrm{gm}$. of calcium. On the tenth day $7 \mathrm{gm}$. of calcium lactate were given, $0.91 \mathrm{gm}$. of calcium. On the eleventh day $9 \mathrm{gm}$. of calcium lactate were given, $1.17 \mathrm{gm}$. of calcium; and on the twelfth day were given $12 \mathrm{gm}$. of calcium lactate, $1.56 \mathrm{gm}$. of calcium. This was followed by a control period of two days.

The accompanying table records the determinations made. The calcium content of the food (milk) was quite constant, as will be seen from the percentage of calcium in milk given in the table. It should be stated that these estimations make the calcium content of milk slightly higher than the figures usually given, which are from 0.149 to 0.198 per cent. The calcium content of the urine was apparently unchanged by the administration of calcium by the mouth. The blood calcium increased perceptibly but slightly during the calcium feeding period. The data obtained from the feces are of doubtful value, not because 
of the method of analysis, but because of our inability to obtain daily stools on account of constipation, and because we erred in that we did not mark the stools. We hoped that the preliminary period of milk feeding before the estimations were begun and the long periods of control and of calcium feeding would enable us to obtain averages which would be of more value than one or two day observations. We were particularly interested in the blood calcium and these data, like those of the milk and urine, we believe are trustworthy and of value.

The following conclusions seem to be justified:

1. The calcium content of the blood in this case of hemophilia is the same as that obtained under normal conditions.

2. The calcium content of the blood increased perceptibly during the calcium feeding period.

3. The coagulation time of the blood was lengthened during the calcium feeding period.

4. The calcium content of the food (milk) was slightly greater in our series than in the usually reported analyses. 